\title{
The Effect of Housing Price on Industrial Agglomeration in China
}

\author{
Zhaohui Li, Xuemei Chen \\ School of Economics, Jinan University, Guangzhou, China \\ Email:18819495995@163.com
}

How to cite this paper: Li, Z.H. and Chen, X.M. (2016) The Effect of Housing Price on Industrial Agglomeration in China. Modern Economy, 7, 1505-1516.

http://dx.doi.org/10.4236/me.2016.712136

Received: October 31, 2016

Accepted: November 15, 2016

Published: November 18, 2016

Copyright $\odot 2016$ by authors and Scientific Research Publishing Inc. This work is licensed under the Creative Commons Attribution International License (CC BY 4.0).

http://creativecommons.org/licenses/by/4.0/

\begin{abstract}
Based on the panel data of 268 prefecture-level cities in China during 2001-2007, this paper examines the impact of housing price on the agglomeration of manufacturing industries in China. Using instrumental variable method to alleviate the endogeneity problem, after controlling for a series of city characteristic variables, the IV regression results show that: the housing price has a significant negative impact on the manufacturing agglomeration. Further studies show that the negative effect mainly comes from the eastern region after 2003 when China's land policy has changed greatly. For the central and western regions, the housing price has no significant effect on the agglomeration.
\end{abstract}

\section{Keywords}

Housing Price, Agglomeration, Immigration

\section{Introduction}

The development of economy is not balanced both within and across countries. Some researches such as Acemoglu et al. (2001) [1] and Redding and Sturm (2008) [2] have attributed the differences of regional economic development to the differences of system, culture or regional advantage. The difference between system and culture is small within a country, but the difference between regional advantages plays a very important role in the development. Fujita and $\mathrm{Hu}$ (2001) [3] have studied the regional development of China in 1985-1994. The results show that in the context of globalization and economic liberalization, the industrial agglomeration, which is caused by the regional advantages of the eastern coastal areas, is the main reason of the huge divergence in economic development between coastal and inland areas. In order to reduce the differences in regional development, the central government of many countries would im- 
plement some place-based policies to improve the advantage of the backward areas [4] [5].

The land policy of China had changed greatly in 2003 to protect land resources and reduce the huge divergence between coastal and inland areas. The control of total land supply was stricter and the supply of land in the central and western regions is increasing. So the supply of land in the East is far behind the growth of population. The eastern region faces a more tense relationship between population and land supply which is the main reason of the rising house price. In the research of Lu et al. (2016) [6], high housing price has pushed up the industrial wage in the east region. Since the development of the manufacture in the East is mainly based on the using of cheap labors, the rising in housing price will inevitably increase the cost of manufacturing enterprises in the East, specifically reflected in the increase in rents and labor costs. Thus, many manufacturing industries cannot bear the high cost and are forced to move to other low-cost areas. From the facts that many low-end manufactures like Foxconn have gradually withdrawn from the East, and are planning to build factors in the west or even in India, we can see that high housing price has hindered the increase of industrial agglomeration of China. According to the study of Lu and Tao (2009) [7], the degree of agglomeration of manufacturing industry in China is rising during 1998-2005, but it is still far below the level of manufacturing agglomeration in the same development period in developed countries. This paper argues the reason of low degree of agglomeration in China. In addition to the local government protectionism pointed out by $\mathrm{Lu}$ and Tao (2009) [7], the high housing price is also an important reason. The purpose of this paper is to investigate the effects of high housing price on manufacturing agglomeration using normative econometric empirical analysis.

\section{Literature Review}

Industrial agglomeration is a very common phenomenon in the real economy. The economic research of the industrial agglomeration is mainly to study the "centripetal force" which is the main driving force for agglomeration and the "centrifugal force" which is the main driving force for dispersion of economic activity. Based on the D-S monopolistic competition model, Krugman (1991) [8] established the Core-Periphery Model. In this model, the interaction between increasing returns to scale, transportation cost and factor mobility leads to the formation and change of spatial distribution of economic activities. But one of the hypotheses is that the agricultural labor force cannot flow across the region, which means the demand of agricultural labor constitutes the main "centrifugal force". What is ignored by this model is that the price of local non tradable goods (e.g. houses) will increase with development.

In Helpman's (1998) [9] model, he allows the agricultural labor flow between regions. Both the consumption of tradable manufacturing products and the nontradable goods (e.g. houses) can increase the utility of workers. When the housing price of a region is too high, it will decrease the utility of workers, thus causing workers to move between regions, changing the degree of industrial agglomeration. An empirical analy- 
sis by Hanson (2005) [10] confirms this conclusion. After that, the empirical research mainly follows the idea of the Helpman-Hanson model. Brakman et al. (2004) [11] and Fan and Shao (2011) [12] applied the Helpman-Hanson model for Germany and China, respectively, to show that housing price is indeed an important dispersive force in economic activity. Glaeser et al. (2006) [13] also confirms the important role of the housing market in the dynamic adjustment of the city. The development of the city relies heavily on the elasticity of local housing supply. When a region is hit by an increase in labor demand, whether new employment opportunities can be transformed to actual employment depends on the ability of the labor force to move to new jobs across regions, which is depending on regional differences between housing price (Zabel, 2012) [14]. The impact of cross-regional labor mobility on local factor prices will adjust the local industry to the type of labor inflows [15] [16].

In the studies above, regional differences in housing price driving labor moving across regions, leading to the change of industrial agglomeration and industrial transfer is the endogenous result in the process of economic development. But the role of government does not take into account. Saks (2008) [17] and Vermeulen and Ommeren (2009) [4] analyze the impact of land policy of government on the labor market in the United States and the Netherlands, respectively. The results show that constraints on land supply affect labor supply and employment in a region. In regions with more restrictive constraints, an increase in labor demand will result in lower employment growth, higher wages and higher housing price. Saiz (2010) [18] uses satellite data to accurately measure the available land in all metropolitan areas in the United States. The results show that restrictions on geographic conditions and land supply policies play an important role in explaining the changes in housing values and the evolution of American cities. An empirical analysis of Finland by Oikarinen et al. (2015) [19] also yielded similar conclusions.

To sum up, in theory, high housing price is the dispersion force of the economic activities according to the study of Krugman (1991) [8] and Helpman's (1998) [9]. Empirical analysis on this subject is divided into two aspects. Some researchers regard this phenomenon as the endogenous result of development. In their studies, the impact of housing price on industrial agglomeration is the inevitable result when the economy develops to a certain degree. They ignored the role of government. Therefore, other researchers take the role of government into account. In their studies, they introduce the impact of external shocks caused by government policy. The restrictions on regional land supply pushes the housing price up, which further hinder the industrial agglomeration and lead to industrial transfer.

For China, land policy is regarded as an important tool of macroeconomic regulatory in 2003. Obviously, China's housing market is largely affected by the regional land policy. But researches on this subject of China have not taken the government policy into account. The innovation of this paper lies in two respects: 1) In the study of the relationship between housing price and industrial agglomeration, this paper first use the micro data of prefecture-level cities in China, which enriches the research in this area. 
2) This paper takes China's land policy into account for the first time, which makes the research more complete. In the following study, we will focus on the eastern region which faces more restrictive constraints of land supply after 2003.

\section{Econometric Model and Data Sources}

\subsection{Econometric Model}

The empirical model of this paper is mainly used to test the impact of housing priceon the agglomeration of manufacturing industries. The basic regression model is:

$$
\operatorname{agg}_{i t}=\beta_{0}+\beta_{1} h p_{i t}+\delta X_{i t}+\eta_{i}+\gamma_{t}+\varepsilon_{i t}
$$

where $a g g_{i t}$ is the manufacturing agglomeration of city $i$ in year $t$, represented by the number of manufacturing workers per unit area of the city (unit: people per square kilometers); $h p_{i t}$ is the commodity housing sales price of city $i$ in year $t$ (unit: yuan/ square meter). It is the core explanatory variable in this paper and $\beta_{1}$ is the core coefficient. $X_{i t}$ is a series of city control variables. $\eta_{i}$ is the city fixed effect and $\gamma_{t}$ is the time fixed effect. $\varepsilon_{i t}$ is the random error. If the regression results show that $\beta_{1}$ is significantly negative after controlling for a series of city characteristic variables, it indicates that housing price do prevent manufacturing agglomeration. The analysis object of this paper is 268 prefecture-level cities and the sample period is 2001-2007.

In order to avoid the problem of omitted variable bias, we add a series of city control variables, $X_{i t}$ includes: 1) Labor market condition (income) is an important factor in the decision of mobility. So we add the total wages of manufacturing industry and per capita GDP of the city into the model to control the impact of labor market conditions. 2) According to Tiebout's (1956) [20] theory of "voting with feet", the labor force will flow for local public services, and empirical evidences from many countries and regions confirm the impact of public services on the decisions of mobility [21] [22] [23]. Therefore, we will put a group of variables representing local public services into the model, including: total number of teachers to represent the education of the city; total number of hospitals and health centers to represent city's medical and health condition; the number of theaters and cinemas to represent the cultural facilities; the number of post offices to represent the communication conditions. 3) We add the number of newly signed foreign contracts of the city into the model to control the impact of foreign direct investment. 4) We use the proportion of tertiary industry to secondary industry to control the city's industrial structure. At last, we use the proportion of urban population to the total population to control urbanization.

The data sources of this paper include: 1) The total number and wage of manufacturing workers come from the "China Annual Survey of Industrial Firms". It is established by the National Bureau of Statistics, and the sample covers all state-owned industrial enterprises and non-state-owned industrial enterprises above the scale, where the above-scale means annual business income (i.e. sales) is 500 million-yuan and above. As the most comprehensive enterprise database in China, it is widely used by scholars. It includes two types of information: one is the basic situation of the enter- 
prise and the other is the financial data of the enterprise. 2) Data of housing price comes from the "China Statistical Yearbook for Regional Economy". It is calculated by dividing the sales of commercial housing by the sales area in the city. It is a large statistical data book which reflects China's regional economic and social development comprehensively and systematically. 3) All other urban variables are derived from the "China City Statistical Yearbook", which is an annual statistical publication that comprehensively reflects the economic and social development of China. It covers all aspects of social economic development and city construction of 656 cities (including prefecture-level cities and county-level cities).

\subsection{Endogenous Problems and Instrumental Variables}

There is an endogeneity problem between the industrial agglomeration and the housing price. On the one hand, as mentioned earlier in this paper, rising housing price will increase the cost of living of urban residents, inhibit the inflow of labor and hinder the further increase of manufacturing agglomeration. On the other hand, the increase of industrial agglomeration will aggravate the competition for limited urban land resources. In the short term, the elasticity of housing supply cannot be increased rapidly to meet the increasing demand, leading to the rise of housing price [9] [11] [24]. In this paper, we try to alleviate the endogeneity problem by finding the instrumental variables of housing price.

The basic idea of instrument regression is to look for exogenous variables that are highly correlated with endogenous variables and influence the interpreted variables only through endogenous variables. We use the land transfer area of the city as an instrumental variable of the housing price. The reason is that land is the most important input in the housing market and land price accounts for a large proportion of the cost of housing. In addition, China has strict land use and protection system. The land supply of the local administrative units is strictly controlled by the central government and the provincial governments. Therefore, the land supply of China is exogenous and the correlation between land supply and manufacturing agglomeration is small. The data of the land transfer area used in this paper is from "China Land and Resources Yearbook". At the same time, due to the good expectations for China's future economic development and real estate market (especially for the eastern region), housing price has a strong stickiness. This means the current housing price is affected largely by previous housing price. So we also use previous housing price as an instrumental variable of current housing price.

\section{Analysis of Regression Results}

\subsection{Results of Overall Sample Regression}

The results of the first stage regression of IV are reported in Table 1. In the first row, the coefficients of the previous housing price $\left(h p_{i t-1}\right)$ are significantly positive. We can see that after controlling for a series of city characteristic variables, the positive effect of previous housing price on current housing price is very significant, indicating that good 
Table 1. The first stage regression of IV.

\begin{tabular}{|c|c|c|c|}
\hline & (1) & (2) & (3) \\
\hline & Whole country $h p_{i t}$ & East $h p_{i t}$ & Midwest $h p_{i t}$ \\
\hline \multirow[t]{2}{*}{$h p_{i t-1}$} & $0.732^{* * *}$ & $0.847^{\star * *}$ & $0.278^{\star * *}$ \\
\hline & $(26.32)$ & (20.75) & $(6.77)$ \\
\hline \multirow[t]{2}{*}{ Land transfer } & $-0.052^{* * *}$ & $-0.060^{* *}$ & 0.007 \\
\hline & $(-2.64)$ & $(-2.20)$ & $(0.2)$ \\
\hline \multirow[t]{2}{*}{ wage } & $0.220^{\star * *}$ & $0.135^{\star * *}$ & $0.932^{* * *}$ \\
\hline & $(5.85)$ & $(2.63)$ & $(6.43)$ \\
\hline Control variables & Yes & Yes & Yes \\
\hline Time fixed effect & Controlled & Controlled & Controlled \\
\hline City fixed effect & Controlled & Controlled & Controlled \\
\hline \multirow[t]{2}{*}{ Constant term } & 95.515 & -144.020 & $630.218^{\star * *}$ \\
\hline & $(0.87)$ & $(-0.68)$ & $(5.09)$ \\
\hline Observations & 1368 & 552 & 816 \\
\hline within $\mathrm{R}^{2}$ & 0.818 & 0.867 & 0.740 \\
\hline First-stage F value & 304.47 & 177.19 & 112.95 \\
\hline
\end{tabular}

expectations for future economic development and the housing market make the housing price very sticky. In the second row, the effect of the land transfer area on the housing price is significantly negative in the sample of the whole country and the East which is consistent with the existing research [6]. The effect of the land transfer area on the housing pricing is positive but not statistically significant in the sample of the central and western regions (Midwest). We think the reason is that the sample period for this paper is from 2001 to 2007, during which the Midwest had abundant land supply and experienced rapid economic growth. The growth of housing price in the Midwest is more likely to be driven by higher incomes from local economic growth. This can be seen from the results of the third column of Table 1, the regression coefficient of wage to housing price is 0.932 for the Midwest, and highly significant at the statistical level of $1 \%$.

Table 2 reports the results of the second-stage of IV regression. After controlling for other city characteristic variables, housing price significantly reduced the degree of agglomeration of manufacturing industry at the national level. The analysis further distinguish between the East and the Midwest shows that the negative effects of housing price on agglomeration are mainly from the east region whose land supply is more restrictive. This means housing price dose inhibit the manufacturing workers flow into the eastern region. While housing price has no significant impact on the agglomeration of manufacturing industry in the Midwest. Let us look at other factors that affect labor mobility and industrial agglomeration. First, the income (wage and per capita GDP) has a significantly positive influence on the industrial agglomeration, indicating that high income is an important factor in the decision of mobility. Secondly, foreign direct 
Table 2. The second stage regression of IV.

\begin{tabular}{|c|c|c|c|}
\hline & (1) & (2) & (3) \\
\hline & Whole country & East & Midwest \\
\hline & agg & agg & agg \\
\hline \multirow[t]{2}{*}{ hp } & $-0.015^{\star * \star}$ & $-0.012^{* * *}$ & 0.002 \\
\hline & $(-5.74)$ & $(-2.95)$ & $(1.22)$ \\
\hline \multirow[t]{2}{*}{ wage } & $0.044^{* * *}$ & $0.030^{\star * *}$ & $0.005^{\star * *}$ \\
\hline & $(15.47)$ & $(6.65)$ & $(2.68)$ \\
\hline \multirow[t]{2}{*}{ Per capita GDP } & $0.002^{* * *}$ & $0.003^{* * *}$ & -0.000 \\
\hline & $(14.89)$ & $(13.20)$ & $(-0.70)$ \\
\hline \multirow[t]{2}{*}{ FDI } & $0.061^{* * *}$ & $0.058^{\star * *}$ & 0.002 \\
\hline & $(8.12)$ & $(5.15)$ & $(0.70)$ \\
\hline \multirow[t]{2}{*}{ Teachers } & $0.000^{*}$ & $0.001^{* *}$ & -0.000 \\
\hline & $(1.83)$ & $(2.32)$ & $(-0.34)$ \\
\hline \multirow[t]{2}{*}{ Hospitals } & 0.007 & 0.008 & -0.001 \\
\hline & $(0.63)$ & $(0.51)$ & $(-0.19)$ \\
\hline \multirow[t]{2}{*}{ Post Offices } & $-0.010^{\star * *}$ & $-0.010^{*}$ & -0.002 \\
\hline & $(-2.78)$ & $(-1.87)$ & $(-0.73)$ \\
\hline \multirow[t]{2}{*}{ Theatres } & -0.097 & -0.004 & -0.022 \\
\hline & $(-1.18)$ & $(-0.03)$ & $(-1.42)$ \\
\hline \multirow[t]{2}{*}{ Urbanization rate } & 2.135 & 23.227 & $-7.230^{* * *}$ \\
\hline & $(0.22)$ & $(1.31)$ & $(-4.66)$ \\
\hline \multirow[t]{2}{*}{ Industrial structure } & -1.131 & -15.201 & -0.009 \\
\hline & $(-0.36)$ & $(-1.38)$ & $(-0.03)$ \\
\hline Time fixed effect & Controlled & Controlled & Controlled \\
\hline City fixed effect & Controlled & Controlled & Controlled \\
\hline \multirow[t]{2}{*}{ Constant term } & -2.796 & $-35.924^{\star *}$ & $12.897^{\star * *}$ \\
\hline & $(-0.36)$ & $(-2.09)$ & $(8.02)$ \\
\hline Observations & 1368 & 552 & 816 \\
\hline Within $\mathrm{R}^{2}$ & 0.679 & 0.740 & 0.154 \\
\hline
\end{tabular}

Note: the lower brackets for the T statistics, ${ }^{* *}$ means significant at $1 \%$ level, ${ }^{* *}$ means significant at $5 \%$ level, * means significant at $10 \%$ level.

investment plays an important role in the development of China, especially for the eastern region. Due to the superior geographical location and the implementation of preferential policies on foreign investment, a large number of foreign capital were attracted to the eastern region. Many factories were built and millions of jobs were created, which attracted a large number of labors to flow into the eastern region and the agglomeration of the manufacturing industry in the eastern region is improved. We can see this from the significantly positive coefficients before FDI in Table 2.

Finally, let us look at the impact of urban public services on manufacturing labor mobility. Of the four variables related to public services, only the coefficients of the 
teachers representing the education are significantly positive, which means good education can attract the labor force into the city and improve the level of manufacturing agglomeration. But the coefficients of the other three variables are not significant or the coefficient sign is negative, which is not consistent with the results of other scholars. We think the reason is that during the sample period we studied, China's manufacturing industry is mainly the low-end manufacturing industry depended on the use of cheap labor. Compared to the urban public service, income, job opportunities, market conditions and government policies are still the main factors of mobility. However, this is not the focus of this paper, so we will not do too much analysis.

\subsection{Regression of Sub Sample}

Since 2003, China's land policy has changed, which pushes housing price up. We will take 2003 as a dividing point to introduce the external impact of policy. We will study the impact of housing price on the agglomeration of manufacturing industries before and after 2003, respectively. The results of regressions are presented in Table 3.

In the first three columns of Table 3, we can see that the coefficients of housing price are not significant in the sample of 2001-2003. This is easy to understand. Housing price did not rise significantly before 2003 , so it had no significant impact on manufacturing agglomeration in this period. But after 2003, affected by the restrictions on land supply, the housing price rose rapidly, especially in the eastern region. In this period, housing price significantly inhibited the increase of manufacturing agglomeration, which can be seen from column 4 . In column 4 , the coefficient of housing price is statistically negative in the regression of national sample. In the fifth and six columns, the coefficient of housing price is significantly negative in the eastern region and is not

Table 3. Changes before and after 2003 (the second stage regression of IV).

\begin{tabular}{|c|c|c|c|c|c|c|}
\hline & (1) & (2) & (3) & $(4)$ & (5) & (6) \\
\hline & \multicolumn{3}{|c|}{$2001-2003$} & \multicolumn{3}{|c|}{ 2004-2007 } \\
\hline & Whole & East & Midwest & Whole & East & Midwest \\
\hline \multirow[t]{2}{*}{ hp } & 0.004 & 0.099 & -0.000 & $-0.007^{\star *}$ & $-0.008^{* *}$ & 0.005 \\
\hline & $(0.39)$ & $(0.59)$ & $(-0.26)$ & $(-2.95)$ & $(-2.25)$ & $(1.56)$ \\
\hline $\begin{array}{c}\text { Control } \\
\text { variables }\end{array}$ & Yes & Yes & Yes & Yes & Yes & Yes \\
\hline $\begin{array}{c}\text { Time fixed } \\
\text { effect }\end{array}$ & Controlled & Controlled & Controlled & Controlled & Controlled & Controlled \\
\hline City fixed effect & Controlled & Controlled & Controlled & Controlled & Controlled & Controlled \\
\hline \multirow[t]{2}{*}{ Constant term } & $-46.472^{\star *}$ & -290.997 & $10.818^{\star * *}$ & $19.098^{* * *}$ & 16.523 & $10.978^{* * *}$ \\
\hline & $(-2.27)$ & $(-0.68)$ & $(2.82)$ & $(3.17)$ & $(1.10)$ & $(2.79)$ \\
\hline Observations & 493 & 195 & 298 & 875 & 357 & 518 \\
\hline within $\mathrm{R}^{2}$ & 0.399 & & 0.074 & 0.716 & 0.738 & \\
\hline
\end{tabular}

Note: the lower brackets for the $\mathrm{T}$ statistics, ${ }^{* *}$ means significant at $1 \%$ level, ${ }^{* *}$ means significant at $5 \%$ level, * means significant at $10 \%$ level. 
significant in the Midwest regions. This suggests that the negative impact of housing price on agglomeration mainly comes from the eastern region.

\subsection{Robustness Test}

In order to investigate the robustness of the results above, we will use per capita land transfer area and the last land transfer area as the instrumental variable of housing price, respectively. The use of per capita land transfer area can control the impact of the city population scale. The use of the last land transfer area can reduce the concern that housing price in turn affecting the supply of land. The regression results of the robustness tests are shown in Table 4 and Table 5.

In Table 4, we examine the robustness of the overall sample period from 2001-2007. Form the magnitude and sign of the coefficients, it can be seen that whichever instrumental variables are used, the results are consistent with the benchmark regression. In Table 5, we divide the sample into two categories, before 2003 and after 2003, to test the robustness of benchmark regression. We get the same conclusion as before.

\section{Conclusions and Future Research}

This paper uses the panel data of 268 prefecture-level cities in China from 2001-2007 to investigate the impact of housing price on industrial agglomeration. In order to alleviate the endogeneity problem, we use the instrumental variable method to estimate the

Table 4. Robustness test (overall sample regression).

\begin{tabular}{|c|c|c|c|}
\hline & $(1)$ & (2) & (3) \\
\hline & \multicolumn{3}{|c|}{ 2001-2007 } \\
\hline & Whole & East & Midwest \\
\hline & per & area as IV & \\
\hline \multirow[t]{2}{*}{ hp } & $-0.015^{\star * *}$ & $-0.011^{* * *}$ & 0.002 \\
\hline & $(-5.57)$ & $(-2.75)$ & $(1.24)$ \\
\hline \multirow[t]{2}{*}{ Constant term } & -3.212 & $-36.854^{* *}$ & $12.871^{* * *}$ \\
\hline & $(-0.42)$ & $(-2.15)$ & $(8.00)$ \\
\hline Observations & 1368 & 552 & 816 \\
\hline \multirow[t]{2}{*}{ Within $\mathrm{R}^{2}$} & 0.680 & 0.741 & 0.153 \\
\hline & \multicolumn{3}{|c|}{ last land transfer area as IV (the second stage) } \\
\hline \multirow[t]{2}{*}{ hp } & $-0.012^{\star * *}$ & $-0.008^{\star *}$ & 0.002 \\
\hline & $(-4.62)$ & $(-2.07)$ & $(1.30)$ \\
\hline \multirow[t]{2}{*}{ Constant term } & -2.348 & $-33.906^{* *}$ & $12.773^{* * *}$ \\
\hline & $(-0.33)$ & $(-2.06)$ & $(8.03)$ \\
\hline Observations & 1376 & 550 & 826 \\
\hline Within $\mathrm{R}^{2}$ & 0.669 & 0.728 & 0.164 \\
\hline
\end{tabular}

Note: The lower brackets for the T statistics, ${ }^{* *}$ means significant at $1 \%$ level, ${ }^{* *}$ means significant at $5 \%$ level, * means significant at $10 \%$ level. Control variables are added to the table above. Time fixed effect and City fixed effect are controlled. 
Table 5. Robustness test (sub sample regression).

\begin{tabular}{|c|c|c|c|c|c|c|}
\hline & $(1)$ & $(2)$ & (3) & $(4)$ & $(5)$ & (6) \\
\hline & \multicolumn{3}{|c|}{$2001-2003$} & \multicolumn{3}{|c|}{$2004-2007$} \\
\hline & Whole & East & Midwest & Whole & East & Midwest \\
\hline & \multicolumn{6}{|c|}{ per capita land transfer area as IV (the second stage) } \\
\hline \multirow[t]{2}{*}{$\mathrm{hp}$} & 0.009 & 0.069 & -0.000 & $-0.006^{* * *}$ & $-0.006^{\star}$ & 0.005 \\
\hline & $(0.76)$ & $(0.57)$ & $(-0.21)$ & $(-2.61)$ & $(-1.92)$ & $(1.62)$ \\
\hline \multirow[t]{2}{*}{ Constantterm } & $-52.989^{* *}$ & -215.991 & $10.769^{* * *}$ & $18.475^{\star * *}$ & 15.141 & $10.663^{* * *}$ \\
\hline & $(-2.52)$ & $(-0.68)$ & $(2.81)$ & $(3.09)$ & $(1.02)$ & $(2.65)$ \\
\hline Observations & 493 & 195 & 298 & 875 & 357 & 518 \\
\hline \multirow[t]{2}{*}{ Within $\mathrm{R}^{2}$} & 0.365 & & 0.075 & 0.720 & 0.744 & \\
\hline & \multicolumn{6}{|c|}{ last land transfer area as IV (the second stage) } \\
\hline \multirow[t]{2}{*}{ hp } & -0.001 & -0.026 & -0.000 & $-0.007^{* * *}$ & $-0.008^{\star *}$ & 0.004 \\
\hline & $(-0.09)$ & $(-0.87)$ & $(-0.21)$ & $(-3.28)$ & $(-2.23)$ & $(1.51)$ \\
\hline \multirow[t]{2}{*}{ Constant term } & $-27.744^{*}$ & 59.285 & $10.762^{* * *}$ & $19.145^{\star * *}$ & 16.082 & $11.784^{* * *}$ \\
\hline & $(-1.75)$ & $(0.78)$ & $(2.81)$ & $(3.23)$ & $(1.08)$ & $(3.46)$ \\
\hline Observations & 493 & 195 & 298 & 883 & 355 & 528 \\
\hline Within $\mathrm{R}^{2}$ & 0.363 & 0.587 & 0.075 & 0.719 & 0.746 & 0.120 \\
\hline
\end{tabular}

Note: the lower brackets for the $\mathrm{T}$ statistics, ${ }^{* *}$ means significant at $1 \%$ level, ${ }^{* *}$ means significant at $5 \%$ level, * means significant at $10 \%$ level. Control variables are added to the table above. Time fixed effect and City fixed effect are controlled.

regression. Since land is the most important input factor in the housing market, we use the city land transfer area as an instrumental variable of housing price. During the period of our study, the prospect for economic development in China is good and the housing price has high stickiness. Therefore, we also use previous housing price as an instrumental variable. After controlling for a series of other city characteristic variables, the IV regression results show that: housing price has a significant negative impact on the manufacturing agglomeration. With the rising of housing price, the cost of labor and rent is pushed up, which damages the competitiveness of the manufacturing industry, thus pushing some enterprises out and hindering further agglomeration. In order to introduce the role of land policy, we divide the sample into two parts: before 2003 and after 2003. The results show that the negative effect of housing price on industrial agglomeration is mainly from the eastern region after 2003 when the land policy has changed. This is easy to understand. The eastern region attracted a large number of international low-end manufactures by cheap factors and preferential policies. As an area of net inflow of population, the increase of land supply is lagging far behind the growth of population, so the manufacturing enterprises of the East suffer the most. Many manufacturing enterprises cannot bear the soaring housing price and the accompanying rising factor price, so many of them withdraw from the East, which is consistent with what we observe in reality. For the Midwest, since it has adequate land supply, the housing price has no significant impact on the manufacturing agglomeration whether 
before or after 2003. Further, we carry out two robustness tests, using the per capita land transfer area and the last land transfer area as the instrumental variables, respectively. The conclusion is consistent with the results of the benchmark regression, which further confirms our conclusion.

There are some limitations to our study. One is that we both use macro and micro data, and there may be some mismatches in the data processing. Besides, we use the number of manufacturing workers per unit area of the city to represent the agglomeration, but it is not an accurate index of agglomeration, which may affect our results. But our research has a strong practical significance. Through this analysis, we can have a better understanding of the relationship between housing price and industrial agglomeration in China, which will contribute to further adjustment of policy. In addition, this is a basic research on housing price and industrial agglomeration in China's special environment, which will promote the further development of research. Agglomeration can improve the production efficiency, but excessive agglomeration can cause congestion which will damage the efficiency. So based on the research of this paper, research on production efficiency will be our future research direction.

\section{Acknowledgements}

We are very grateful for those who helped us in the writing of the thesis. Firstly, we want to give our sincere thanks to my teacher Dai Tianshi who gave us valuable help with the data. Then, we want to thank Zhou Kang and Dr. You Jihong for their valuable advices. Finally, we are very appreciating for the editor and anonymous referees for their insightful comments and advices. The authors take sole responsibility for this article.

\section{References}

[1] Acemoglu, D., Johnson, S. and Robinson, J.A. (2001) The Colonial Origins of Comparative Development: An Empirical Investigation. The American Economic Review, 91, 1369-1401. https:/doi.org/10.1257/aer.91.5.1369

[2] Redding, S.J. and Sturm, D.M. (2008) The Costs of Remoteness: Evidence from German Division and Reunification. The American Economic Review, 98, 1766-1797. https:/doi.org/10.1257/aer.98.5.1766

[3] Fujita, M. and Hu, D. (2001) Regional Disparity in China 1985-1994: The Effects of Globalization and Economic Liberalization. The Annals of Regional Science, 35, 3-37. https:/doi.org/10.1007/s001680000020

[4] Vermeulen, W. and Ommeren, J. (2009) Does Land Use Planning Shape Regional Economies? A Simultaneous Analysis of Housing Supply, Internal Migration and Local Employment Growth in the Netherlands. Journal of Housing Economics, 18, 294-310. https:/doi.org/10.1016/j.jhe.2009.09.002

[5] Kline, P. and Moretti, E. (2014) Local Economic Development, Agglomeration Economies, and the Big Push: 100 Years of Evidence from the Tennessee Valley Authority. Quarterly Journal of Economics, 128, 275-331. https:/doi.org/10.1093/qje/qjt034

[6] Liang, W., Lu, M. and Zhang, H. (2016) Housing Prices Raise Wages: Estimating the Unexpected Effects of Land Supply Regulation in China. Journal of Housing Economics, 33, 
70-81. https:/doi.org/10.1016/j.jhe.2016.07.002

[7] Lu, J. and Tao, Z. (2009) Trends and Determinants of China's Industrial Agglomeration. Journal of Urban Economics, 65, 167-180. https:/doi.org/10.1016/j.jue.2008.10.003

[8] Krugman, P. (1991) Increasing Returns and Economic Geography. The Journal of Political Economy, 99, 483-499. https:/doi.org/10.1086/261763

[9] Helpman, E. (1998) The Size of Regions. In: Pines, D., Sadka. E. and Zilcha, I., Eds., Topics in Public Economics: Theoretical and Applied Analysis, Cambridge University Press, Cambridge, 33-54.

[10] Hanson, G.H. (2005) Market Potential, Increasing Returns and Geographic Concentration. Journal of International Economics, 67, 1-24. https:/doi.org/10.1016/j.jinteco.2004.09.008

[11] Brakman, S., Garretsen, H. and Schramm, M. (2004) The Spatial Distribution of Wages: Estimating the Helpman-Hanson Model for Germany. Journal of Regional Science, 44, 437466. https:/doi.org/10.1111/j.0022-4146.2004.00344.x

[12] Fan, J. and Shao, T. (2011) Housing Price, Location of Diversified Product and Urban System. Economic Research Journal, 2, 87-99.

[13] Glaeser, E.L., Gyourko, J. and Saks, R.E. (2006) Urban Growth and Housing Supply. Journal of Economic Geography, 6, 71-89. https:/doi.org/10.1093/jeg/lbi003

[14] Zabel, J.E. (2012) Migration, Housing Market, and Labor Market Responses to Employment Shocks. Journal of Urban Economics, 72, 267-284. https:/doi.org/10.1016/j.jue.2012.05.006

[15] Hanson, G.H. and Slaughter, M.J. (1999) The Rybczynski Theorem, Factor-Price Equalization, and Immigration: Evidence from US States. NBER Working Paper No. W7074.

[16] Skiba, A. (2006) Immigration, Firm Relocation and Welfare of Domestic Workers. 6th Annual Missouri Economics Conference, Columbia, 31 March-1 April 2006.

[17] Saks, R.E. (2008) Job Creation and Housing Construction: Constraints on Metropolitan Area Employment Growth. Journal of Urban Economics, 64, 178-195. https:/doi.org/10.1016/j.jue.2007.12.003

[18] Saiz, A. (2010) The Geographic Determinants of Housing Supply. The Quarterly Journal of Economics, 125, 1253-1296. https:/doi.org/10.1162/qjec.2010.125.3.1253

[19] Oikarinen, E., Peltola, R. and Valtonen,E. (2015) Regional Variation in the Elasticity of Supply of Housing, and Its Determinants: The Case of a Small Sparsely Populated Country. Regional Science and Urban Economics, 50, 18-30. https:/doi.org/10.1016/j.regsciurbeco.2014.10.004

[20] Tiebout, C.M. (1956) A Pure Theory of Local Expenditures. The Journal of Political Economy, 64, 416-424. https:/doi.org/10.1086/257839

[21] Nechyba, T.J. and Strauss, R.P. (1998) Community Choice and Local Public Services: A Discrete Choice Approach. Regional Science and Urban Economics, 28, 51-73. https:/doi.org/10.1016/S0166-0462(97)00013-6

[22] Bayoh, I., Irwin, E.G. and Haab, T. (2006) Determinants of Residential Location Choice: How Important Are Local Public Goods in Attracting Homeowners to Central City Locations? Journal of Regional Science, 46, 97-120. https:/doi.org/10.1111/j.0022-4146.2006.00434.x

[23] Xia, Y. and Lu, M. (2015) City Choices: An Empirical Study on How Public Services Affect Labor Flow. Management World, 10, 78-90.

[24] Fan, H. (2008) The Ineffective of Public Policies and Excessive Concentration of Production and Population. Economic Research Journal, 6, 73-84. 
Submit or recommend next manuscript to SCIRP and we will provide best service for you:

Accepting pre-submission inquiries through Email, Facebook, LinkedIn, Twitter, etc.

A wide selection of journals (inclusive of 9 subjects, more than 200 journals)

Providing 24-hour high-quality service

User-friendly online submission system

Fair and swift peer-review system

Efficient typesetting and proofreading procedure

Display of the result of downloads and visits, as well as the number of cited articles

Maximum dissemination of your research work

Submit your manuscript at: http://papersubmission.scirp.org/

Or contact me@scirp.org 